\title{
The Relationship Between Moment and Curvature and the Elastic-Plastic Seismic Response Analysis of High Pier Section
}

\author{
Jinxue Jun ${ }^{*}, 1$ and Wanggen $\mathrm{Hui}^{2}$ \\ ${ }^{1}$ Lanzhou Jiaotong University, Lanzhou 730070, China \\ ${ }^{2}$ Key Laboratory of Road \& Bridge and Underground Engineering of Gansu Province 730070, China
}

\begin{abstract}
Nonlinear hysteresis characteristics are usually utilized in the elastic-plastic seismic analysis of the structure of bridge. These characteristics may be described by the relationship of section bending moment and curvature. This relationship can be obtained by the section size and reinforcement, which is also a simple and time-saving method to evaluate the seismic behavior of the section. The research is conducted on the effect of section bending moment and curvature. Then, five different sections are chosen to observe their effects on bending moment and curvature. The results indicate that with the increase in section size, the crack, the yield, the moment damage and the curvature of the section also increase. The increase in section size refers to the increase in moment of inertia, so with the increase in the moment of inertia, the resistance to crack, field and damage of the bridge pier become stronger. On this basis, the elastic-plastic time history analysis of $\mathrm{Wu}$ Guan super highway Gan Gou Zi Bridge is carried out. It shows that the capacity of energy dissipation by hysteretic of the Rectangular thin-wall pier is better than the twin shaft pier. So it is best to use rectangular thin-wall pier in the same condition.
\end{abstract}

Keywords: Analysis of elastic-plastic, high pier, moment and curvature, seismic.

\section{INTRODUCTION}

The relationship between bending moment and curvature of reinforced concrete member is the basis for elastic-plastic seismic analysis of the reinforced concrete structure. Since the bending destruction ductility of reinforced concrete structure is good, the design usually uses the method of bending strength lower than shear strength to prevent the collapse and destruction of the bridge. The destruction of the structure is mainly controlled by bending destruction, and the plastic behavior mainly depends on the characteristics of bending deformation [1].

In elastic-plastic seismic analysis of the bridge structure, nonlinear hysteretic characteristics are frequently used, and nonlinear hysteretic characteristics of beam section or column section can be described by the cross-section bending moment-curvature relation or the load-displacement relationship curve. The bending moment-curvature curve can be widely applied in cross-section seismic analysis of reinforced concrete as the seismic performance that evaluates the cross-section. The bending moment-curvature curve is obtained by section size and reinforcement. The method of using this curve to evaluate the cross-section seismic performance is simple and able to save the analysis time.

\section{CONSTITUTIVE RELATION FOR MATERIALS}

The numerical analysis result of cross-section bending moment-curvature curve and elastic-plastic analysis process

*Address correspondence to this author at the Lanzhou Jiaotong University, Lanzhou 730070, China; Tel: +8618009319368;

E-mail: 1849294392@qq.com of reinforced concrete structure largely depend on the selection of constitutive model of concrete materials as well as on the judgment of yield curvature and ultimate curvature. The concrete is divided into unconstrained concrete and confined concrete with different mechanical properties.

\subsection{Mechanical Properties of Unconstrained Concrete}

Under the effect of ground motion, concrete structure would experience the cyclic deformation cycle. Upon conducting massive experimental studies, some important phenomena and laws regarding cyclic loading are obtained. The enveloping line (skeleton curve) is the smooth curve drawn along the outer contour of concrete stress-strain curves under cyclic loading (deformation). It is found from the experiment that under the effect of cyclic loading, the enveloping line of stress-strain curves of unconstrained concrete is much close to the complete curves of monotonic loading, and the compression strength and peak strain given by the peak point on the enveloping line have no obvious difference from the peak value of monotonic loading. Therefore, the stress-strain curves under cyclic loading can be taken as the corresponding curves under the monotonic loading [2]. Fig. (1) shows the stress-strain curves of unconstrained concrete.

\subsection{Mechanical Properties of Confined Concrete}

In most cases, the ultimate compression strain of unconstrained concrete cannot ensure the expected plastic capacity of the plastic hinge area of the pier. When the outmost concrete of the cross-section of plastic hinge area reaches the crushing strain, the concrete protective layer 
begins to peel first; if the core concrete is not sufficiently confined, the longitudinal crack extends to the core area rapidly, resulting in transverse expansion of the concrete, thus to cause the compression area of core concrete to be crushed. For reinforced concrete bridge piers, due to suffering of high axial compression ratio, the expansion of longitudinal crack causes the bending of longitudinal compression reinforcement. Therefore, for the reinforced concrete bridge piers designed with the concept of unconstrained concrete, once the utmost concrete of crosssection of plastic hinge area reaches the ultimate compression strain value, it implies that the pier has reached the ultimate state of destruction. Since the ultimate compression strain of unconstrained concrete is low, the maximum plastic rotation of cross-section is also low, thus being unable to provide the displacement ductility of the structure needed under the ground motion.

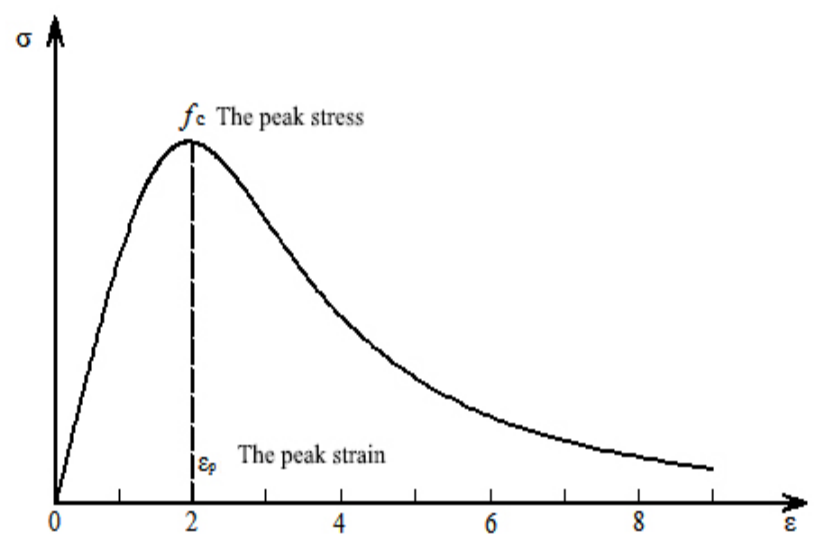

Fig. (1). Unconstrained concrete monotonic loading stress-strain curves.

A sufficient number of transverse stirrups and longitudinal reinforcement can be allocated to play a role in confinement of the core concrete, effectively restricting the transverse expansion of concrete, keeping the integral of core concrete, improving the ultimate compression stress of core concrete, and preventing the bending of longitudinal reinforcement. More importantly, before the core concrete compression area is destroyed, the compression strain is maintained much higher than the unconstrained concrete. Therefore, the concept of confined concrete is usually used to design the reinforced concrete ductile bridge pier.

When using the concept of confined concrete for the design of members, the compression stress-strain relation of the confined concrete should be known. So far, domestic and foreign scholars have carried out many experimental studies, and put forward many different stress-strain curves. Among these constitutive relations, some are built on the basis of theoretical derivation, some are built on the basis of numerical calculation, and some are built on the basis of semi theoretical and semi empirical formula.

Kent and R. Park et al. suggested the stress-strain curve of the concrete confined by rectangular closed stirrup according to experimental results, which is widely applied since well accorded with the experimental results. This paper uses concrete constitutive model of Kent-Park for analysis. As shown in Fig. (2), the relations of each section are shown as follows:

\section{OA Section:}

$\sigma=f_{c}\left[\frac{2 \varepsilon}{0.002}-\left(\frac{\varepsilon}{0.002}\right)^{2}\right] \varepsilon \leq 0.002$

AB Section:

$\sigma=f_{c}[1-Z(\varepsilon-0.002)] 0.002 \leq \varepsilon \leq \varepsilon_{50}$

BC Section:

$\sigma=0.2 f_{c} \varepsilon \geq \varepsilon_{50}$

The Parameter $\mathrm{Z}$ of $\mathrm{AB}$ Section is determined by the following formula:

$$
\begin{aligned}
& Z=\frac{0.5}{\varepsilon_{20 u}+\varepsilon_{20 h}-0.002} \\
& \varepsilon_{20 u}=\frac{3+0.29 f_{c}}{145 f_{c}-1000} \\
& \varepsilon_{20 h}=\frac{3}{4} \rho_{v} \sqrt{\frac{b}{s}}
\end{aligned}
$$

In the formula: $\rho_{v}$ indicates the volume ratio of the stirrup to the concrete confined by the stirrup;

$b$ indicates the concrete width confined by the stirrup;

$s$ indicates the stirrup spacing;

$f_{c}$ indicates the compression strength of concrete cylinder (MPa).

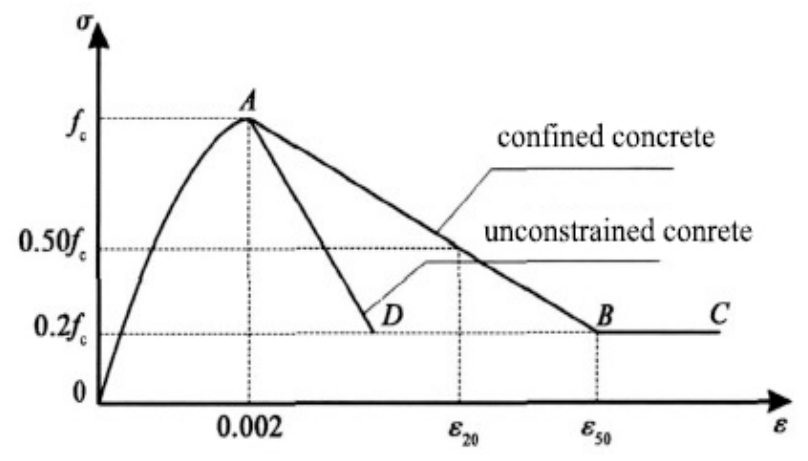

Fig. (2). Confined concrete stress-strain curves.

\subsection{Stress-Strain Relations for Reinforcement}

According to the above stress-strain relation, the constitutive relation of reinforcement material is simplified in the structure calculation, and there are mainly three common restoring force models of reinforcement material, as shown in Fig. (3) [3, 4].

(1) Ideal elastic-plastic model (namely, double-line model);

(2) Elastic-consolidation model (namely, double-slash model);

(3) Elastic-plastic-consolidation model (namely, triplebroken line model); 


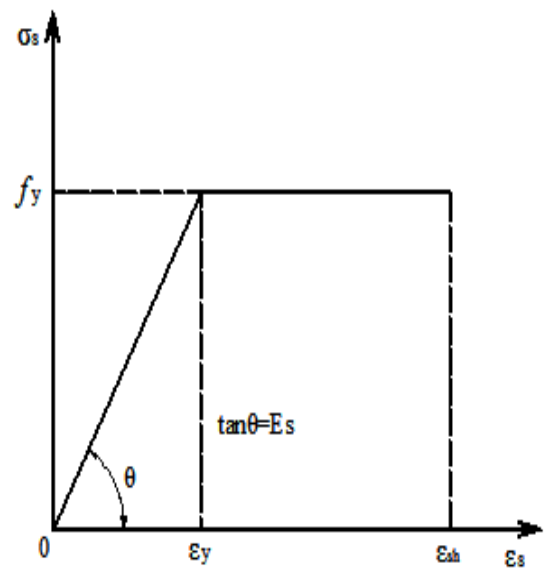

(a) Ideal elastic-plastic

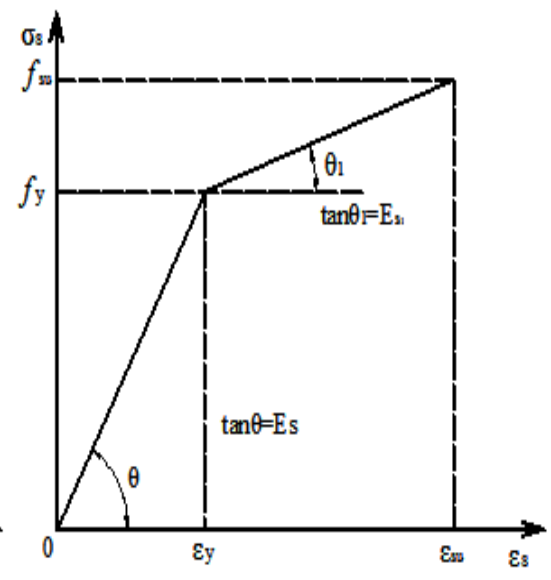

(b) Elastic-consolidation

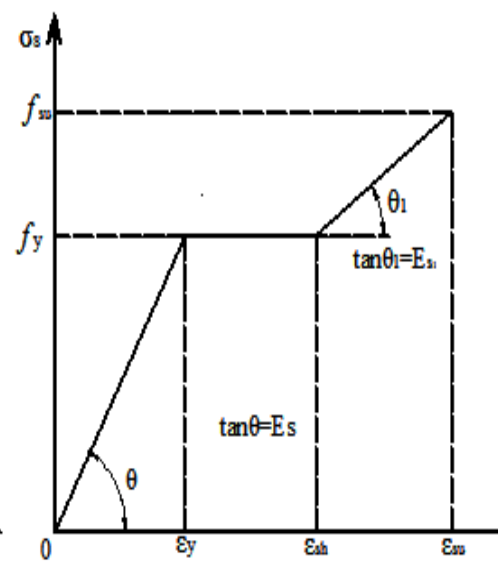

(c) Elastic-plastic-consolidation

Fig. (3). Reinforcement constitutive model.

This paper uses the elastic-consolidation constitutive model for elastic-plastic analysis, and the mathematical expression is:

When

$\varepsilon_{s} \leq \varepsilon_{y}, \sigma_{s}=E_{s} \varepsilon_{s}$

When

$\varepsilon_{y} \leq \varepsilon_{s} \leq \varepsilon_{s u}, \sigma_{s}=f_{y}+E_{s 1}\left(\varepsilon_{s}-\varepsilon_{y}\right)$

Elastic modulus:

$$
\begin{aligned}
& E_{s}=\frac{f_{y}}{\varepsilon_{y}} \\
& E_{s 1}=\frac{f_{s u}-f_{y}}{\varepsilon_{s u}-\varepsilon_{y}}
\end{aligned}
$$

In the formula: $E_{s}$ indicates the elastic modulus;

$E_{s 1}$ indicates the elastic modulus of the reinforcement at consolidation stage, generally taken as $0.01 E_{s}$;

$f_{y}$ indicates the design value of tensile strength of the reinforcement $\left(\mathrm{N} / \mathrm{mm}^{2}\right)$;

$\varepsilon_{y}$ indicates the yield strain corresponding to the yield strength.

\subsection{Restoring Force Model of Cross-Section}

In the elastic-plastic analysis of the structure, the determination of restoring force model is the most fundamental, while the restoring force relation of the member is reflected in the hysteretic characteristic curve, including curve shape, skeleton curve, stiffness and strength degradation law as well as hysteretic damping coefficient. There are three types of hysteretic characteristic models of reinforced concrete: The first type is the model obtained by simplification of material test curves, mainly including double-line, triple-line or multi-line model; the second type is peak point model of origin pointing and material degradation characteristics; and the third type is the combination model of the first type and the second type [5].

Clough put forward the double-line model considering member stiffness degradation effect in 1965 [6,7], which is simple and able to reflect the stiffness degradation effect under the effect of ground motion largely, thus to be widely applied. Takeda et al. abstracted the model of complex triple-line stiffness degradation mainly focusing on bending destruction according to restoring force characteristics of various tests on reinforced concrete member. This model has complex primary and secondary hysteretic laws, and the skeleton curve is composed of three sections of straight line, namely, the first section of line is used at the elastic stage before cracking, the second section of line is used after cracking of concrete, and the third section of line is used after yield of longitudinal reinforcement. Fig. (4) shows the triple-line restoring force model of Takeda.

This paper uses the triple-line model of Takeda.

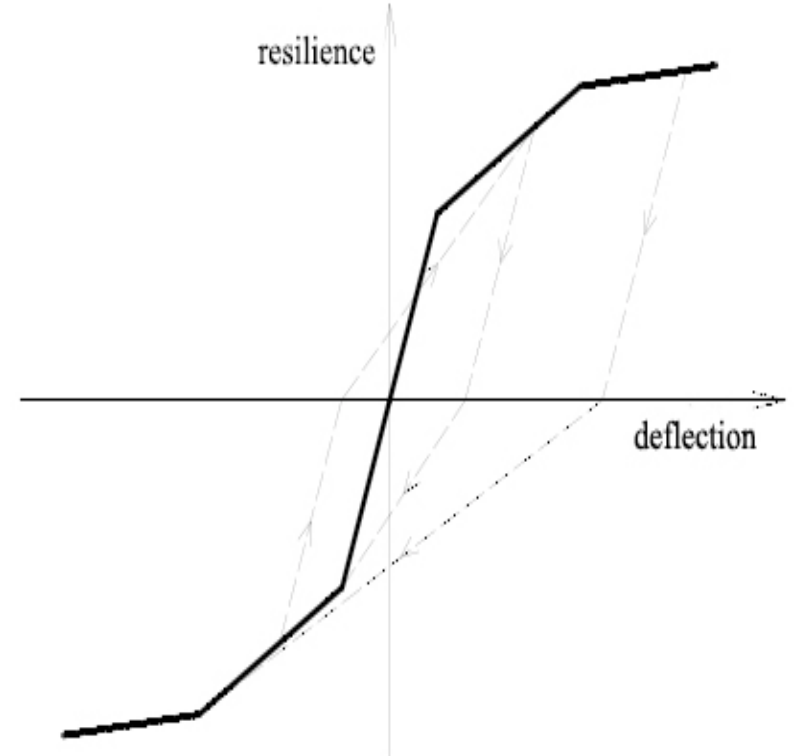

Fig. (4). Takeda three linear restoring force model. 


\section{ANALYSIS OF CROSS-SECTION BENDING MOMENT-CURVTURE OF BRIDGE PIER}

The analysis of cross-section bending moment-curvature is the basic analysis tool for determining ductility capacity of member curvature, which is necessary for prediction of plastic deformation capacity of the bridge pier. Through the analysis of cross-section bending moment-curvature, the curvature ductility factor of plastic hinge area is determined in theory.

For the analysis of cross-section bending momentcurvature, the following assumptions are generally made:

From stress to destruction of the plane-section assumption-member, the cross-section always keeps the plane during the deformation process;

(2) The impact caused by the shear and deformation of member is not taken into consideration;

(3) The bond slip between the reinforcement and concrete of member is not taken into consideration;

Selecting the rectangular thin-wall hollow pier as the calculation object, the change in cross-section size and the impact on the bending moment-curvature are observed; therefore, five cross-section sizes are selected: wall thickness is $0.5 \mathrm{~m}$, longitudinal dimension is $\mathrm{H}$ and transverse dimension is B. The cross-sectional shape is the octagonal section within the rectangular, and the chamfer dimension is $0.2 \mathrm{~m}$. (1) $\mathrm{H}=2.1 \mathrm{~m}, \mathrm{~B}=5 \mathrm{~m} ;$ (2) $\mathrm{H}=2.3 \mathrm{~m}, \mathrm{~B}=5.5 \mathrm{~m}$; (3) $\mathrm{H}=2.5 \mathrm{~m}, \mathrm{~B}=6 \mathrm{~m}$; (4) $\mathrm{H}=2.7 \mathrm{~m}, \mathrm{~B}=6.5 \mathrm{~m}$; (5) $\mathrm{H}=2.9 \mathrm{~m}, \mathrm{~B}=7 \mathrm{~m}$. Kent-Park Model is used for confined concrete, and the elastic-consolidation constitutive model is used for the reinforcement. Concrete $\mathrm{C} 40$ is used, and reinforcement
HRB335 is used. The characteristic value parameters are shown in Table $\mathbf{1}$, the calculation results are shown in Table $\mathbf{2}$, and the diagram of bending moment-curvature is shown in Fig. (5).

Diagram of Bending Moment-Curvature Curves of Each Section:

It shows from Table $\mathbf{1}$ and Fig. (5) that with the increase in section size, the change in bending moment-curvature of the section is obvious, and the cracking, yield and destruction bending moment and curvature increase accordingly. The increase in section size is the increase in cross-section moment of inertia; therefore, with the increase in moment of inertia of pier section, the anti-cracking, yield and destruction capacity become stronger. Based on this, the analysis of elastic-plastic time history of this bridge is made.

\section{CALCULATION RESULTS OF ELASTIC- PLASTIC TIME HISTORY OF PIER AND THE ANALYSIS}

\subsection{Bridge Introduction}

This paper uses the finite element analysis software MIDAS/Civil to build the model and to carry out elasticplastic time history analysis of piers of Wu Guan super highway Gan Gou Zi Bridge. The maximum height of the bridge pier is $49 \mathrm{~m}$, and the minimum height of the bridge pier is $14 \mathrm{~m}$, in which No.1 Pier and No.6 Pier are doublecolumn bridge piers, and No.2 Pier, No.3 Pier, No.4 Pier and No.5 Pier are rectangular thin-wall hollow piers. All the foundations of the whole bridge are pile foundations. The heights of piers from No.1 Pier to No.6 Pier are $25 \mathrm{~m}, 49 \mathrm{~m}$,

Table 1. Material parameters in property values.

\begin{tabular}{|c|c|c|c|}
\hline Standard Strength & Item & Value & Unit \\
\hline \multirow{3}{*}{$\begin{array}{c}\text { Concrete C40 } \\
f_{c k}=26.8 \mathrm{MPa}\end{array}$} & Yield Compression Strain of Concrete & 0.02 & - \\
\hline & Ultimate Compression Strain of Concrete & 0.05 & - \\
\hline & Standard Value of Concrete Compressive Strength & 26.8 & $\mathrm{MPa}$ \\
\hline \multirow{4}{*}{ Steel HRB335 } & Yield Strain of Reinforcement & 0.0015 & - \\
\hline & Ultimate Strain of Reinforcement & 0.01 & - \\
\hline & Yield strength of Reinforcement & 335 & $\mathrm{MPa}$ \\
\hline & Ultimate strength of Reinforcement & 455 & $\mathrm{MPa}$ \\
\hline
\end{tabular}

Table 2. Calculation results of bending moment-curvature.

\begin{tabular}{|c|c|c|c|c|c|c|}
\hline \multirow{2}{*}{ Section } & \multicolumn{2}{|c|}{ Cracking } & \multicolumn{2}{|c|}{ Yield } & \multicolumn{2}{|c|}{ Destruction } \\
\hline & $\begin{array}{c}\text { Bending Moment } \\
\text { (kN.m) }\end{array}$ & Curvature (rad/m) & $\begin{array}{c}\text { Bending Moment } \\
\text { (kN.m) }\end{array}$ & Curvature (rad/m) & $\begin{array}{c}\text { Bending Moment } \\
\text { (kN.m) }\end{array}$ & Curvature ( $\mathrm{rad} / \mathrm{m})$ \\
\hline 1 & 11197.46 & 0.00079 & 19057.19 & 0.00143 & 20299.27 & 0.00306 \\
\hline 2 & 17522.87 & 0.00087 & 24364.37 & 0.00121 & 26005.63 & 0.00283 \\
\hline 3 & 17480.25 & 0.00083 & 29094.04 & 0.00124 & 30898.06 & 0.00260 \\
\hline 4 & 19534.56 & 0.00053 & 34711.86 & 0.00107 & 37043.34 & 0.00243 \\
\hline 5 & 25559.90 & 0.00063 & 39358.67 & 0.00100 & 42004.52 & 0.00227 \\
\hline
\end{tabular}


(a) Bending moment-curvature of No. 1 section

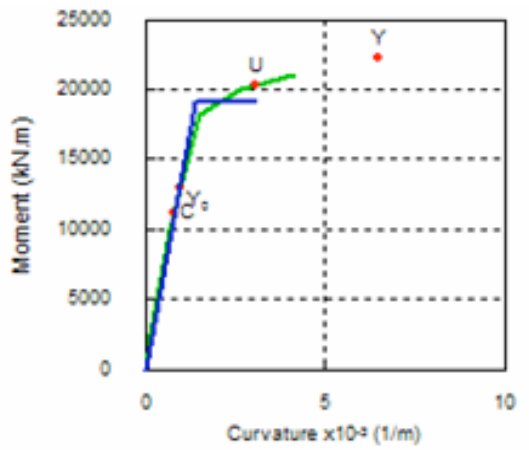

(c) Bending moment-curvature of No. 3 section

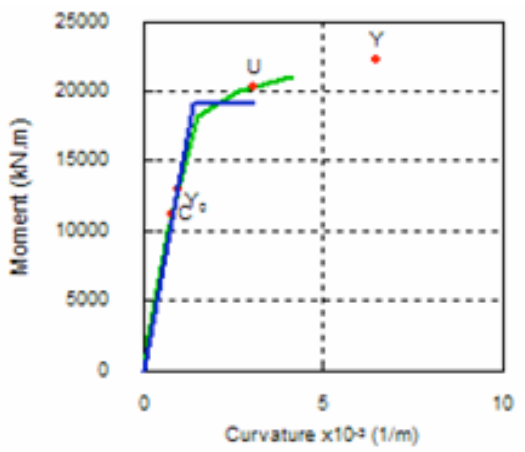

(b) Bending moment-curvature of No. 2 section

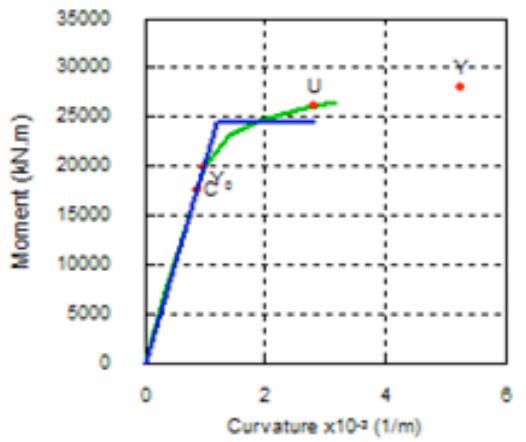

(d) Bending moment-curvature of No. 4 section

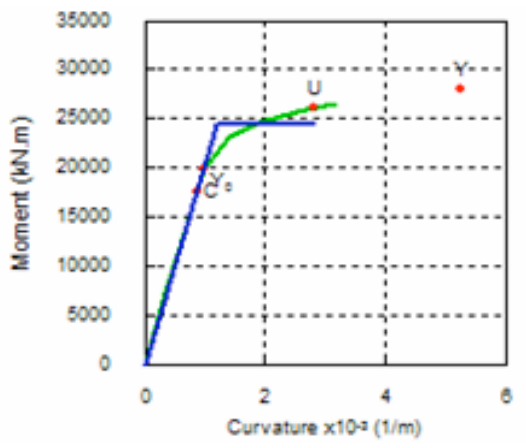

(e) Bending moment-curvature of No. 5 section

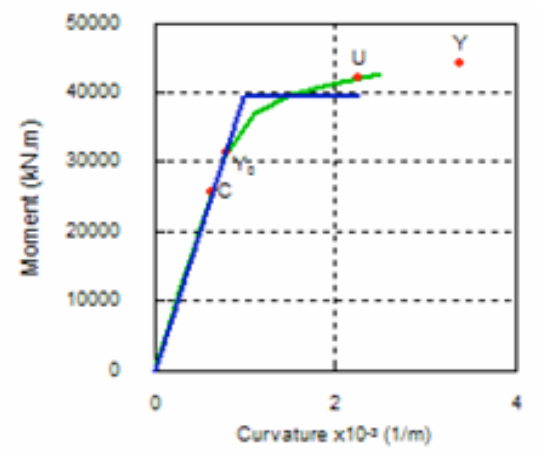

Fig. (5). Bending moment-curvature of each section.

$34 \mathrm{~m}, 23 \mathrm{~m}, 19 \mathrm{~m}$ and $14 \mathrm{~m}$ respectively. The finite element model of the whole bridge is shown in Fig. (6). According to relevant regulations in Guidelines for Seismic Design of Highway Bridges (JTG/TB02-01-2008) of China, the deformation under E2 seismic effect and ductile deformation capacity of plastic hinge area should be checked for $\mathrm{B}$ and $\mathrm{C}$ type bridge pier column.

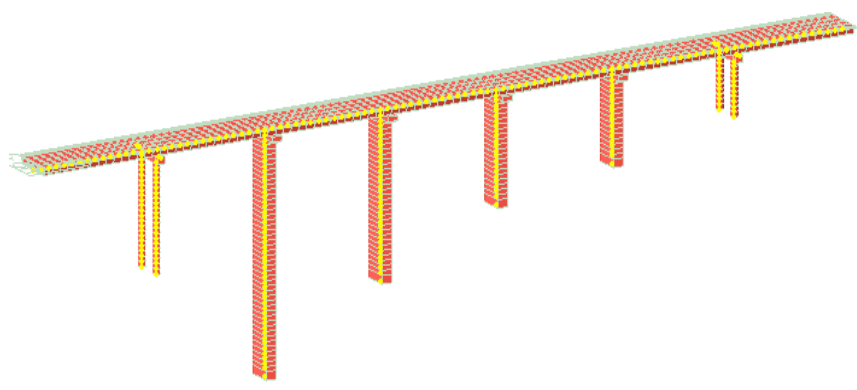

Fig. (6). Elastic-plastic analysis model of the bridge.

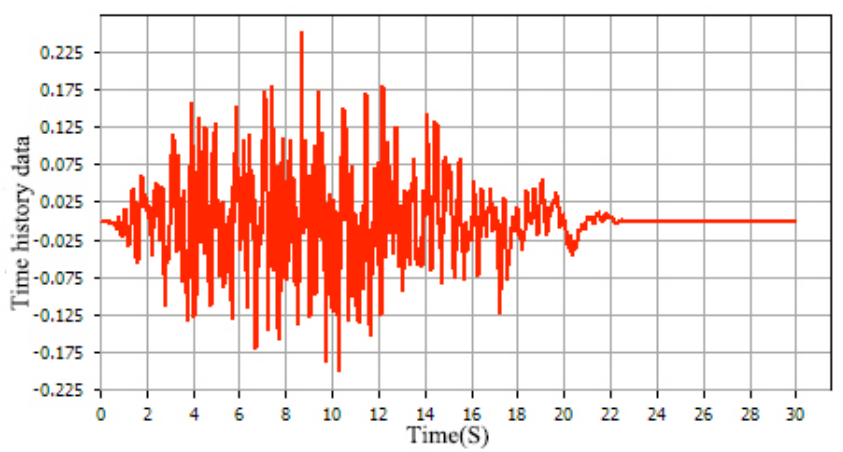

Fig. (7). E2 Seismic time-travel curves.

For selection of ground motion time history, the safety evaluation seismic wave is selected for analysis according to Seismic Safety Evaluation Report of Important Bridge Engineering Site of Wudu to Guanzigou Highway Liangshui-Luotang Section. Fig. (7) shows the seismic wave 
(a) Bending moment-curvature hysteretic diagram of No.1 pier

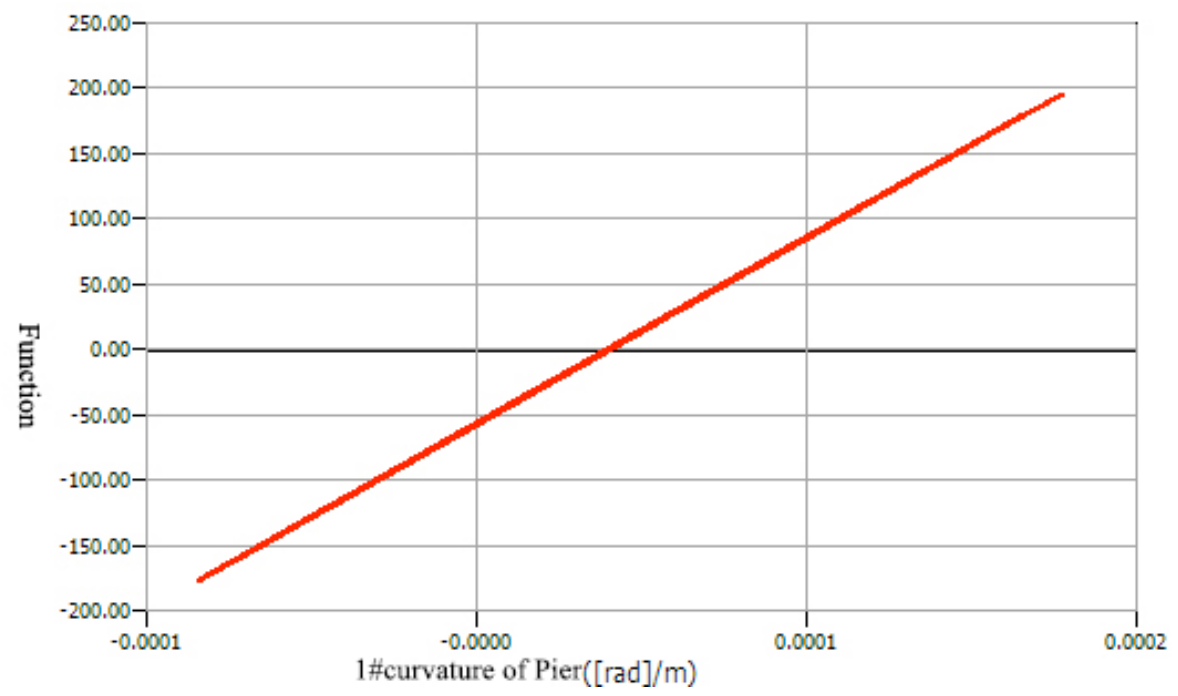

1 * Bending moment of Pier

- Summary -

* Max: $1.964 e+002$ at 0.000

* Min:-1.774e+002 at -0.000

* Unit: $k N, m, s e c$

(b) Bending moment-curvature hysteretic diagram of No.2 pier

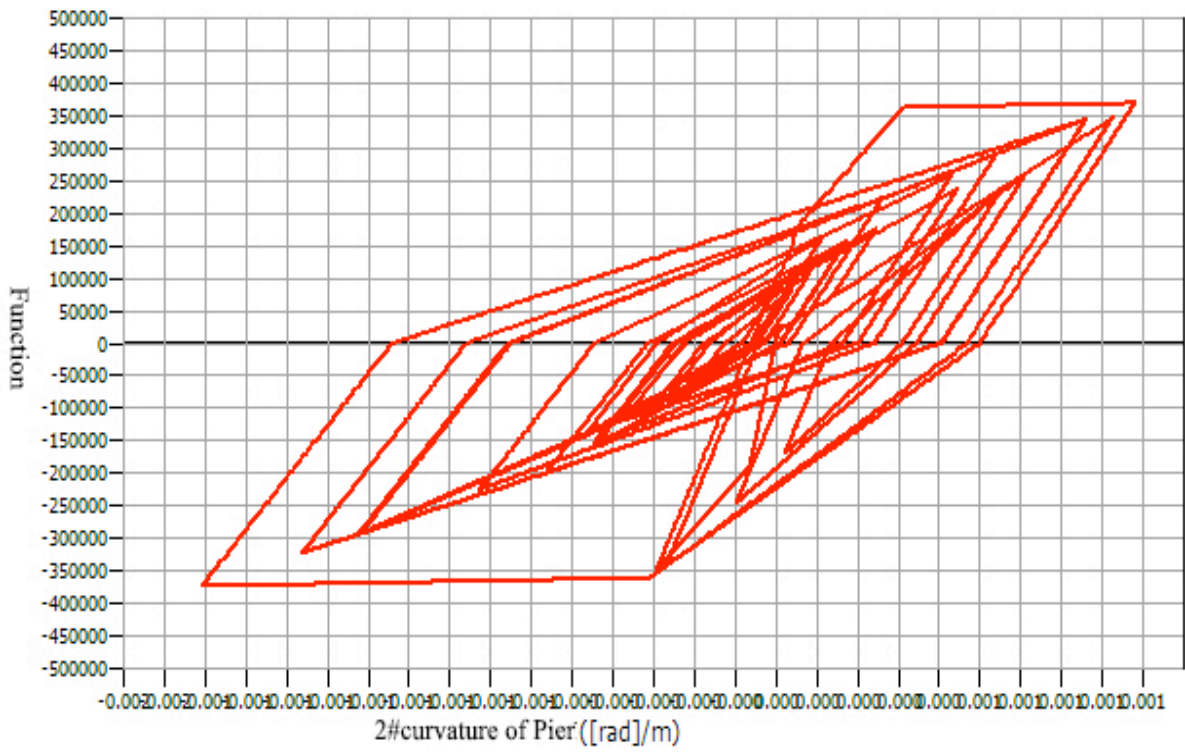

2 *Bending moment of Pier

- Summary -

* Max:3.682e+005 at 0.001

* Min:-3.742e+005 at -0.001

*Unit:kN,m,sec

(c) Bending moment-curvature hysteretic diagram of No.3 pier

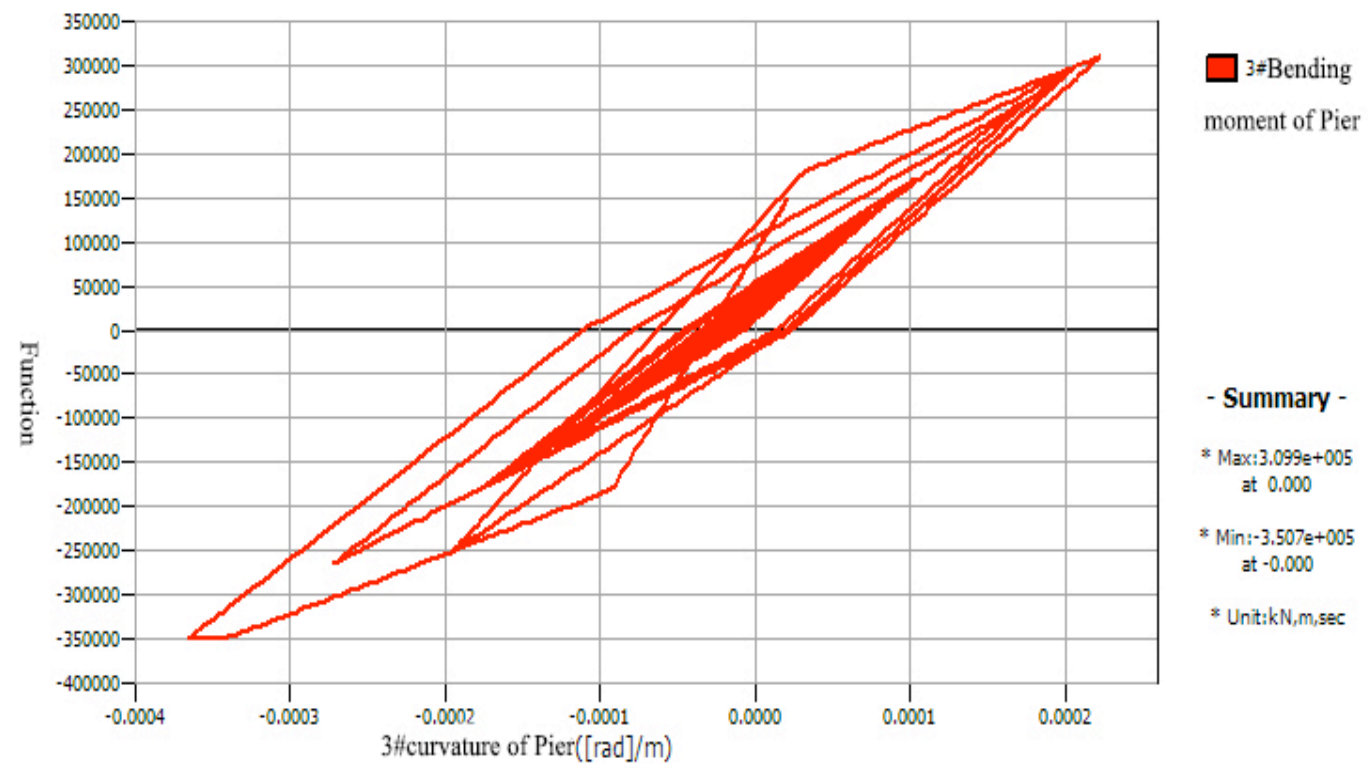


(Fig. 8) contd.....

(d) Bending moment-curvature hysteretic diagram of No.4 pier

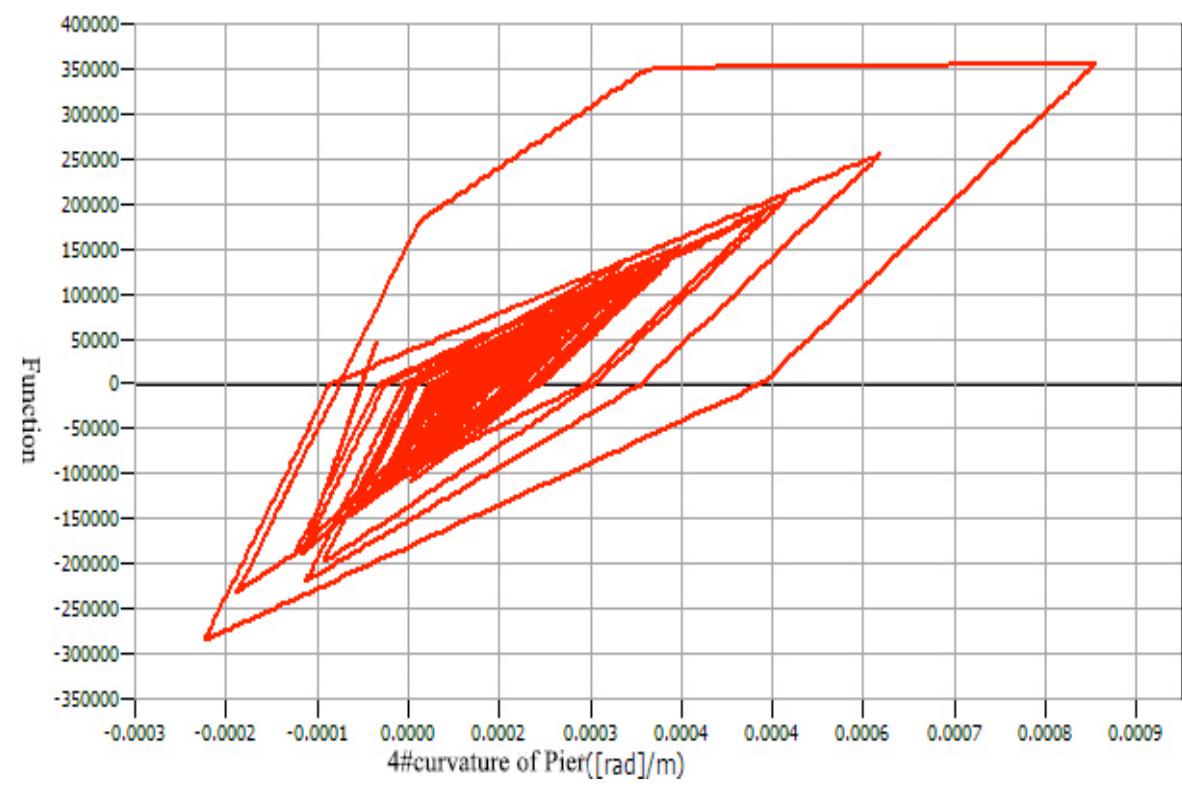

4* Bending

moment of Pier

- Summary -

* Max:3,551e+005 at 0.001

* Min:-2,855e+005 at $-0,000$

* Unit:kN,m,sec

(e) Bending moment-curvature hysteretic diagram of No.5 pier

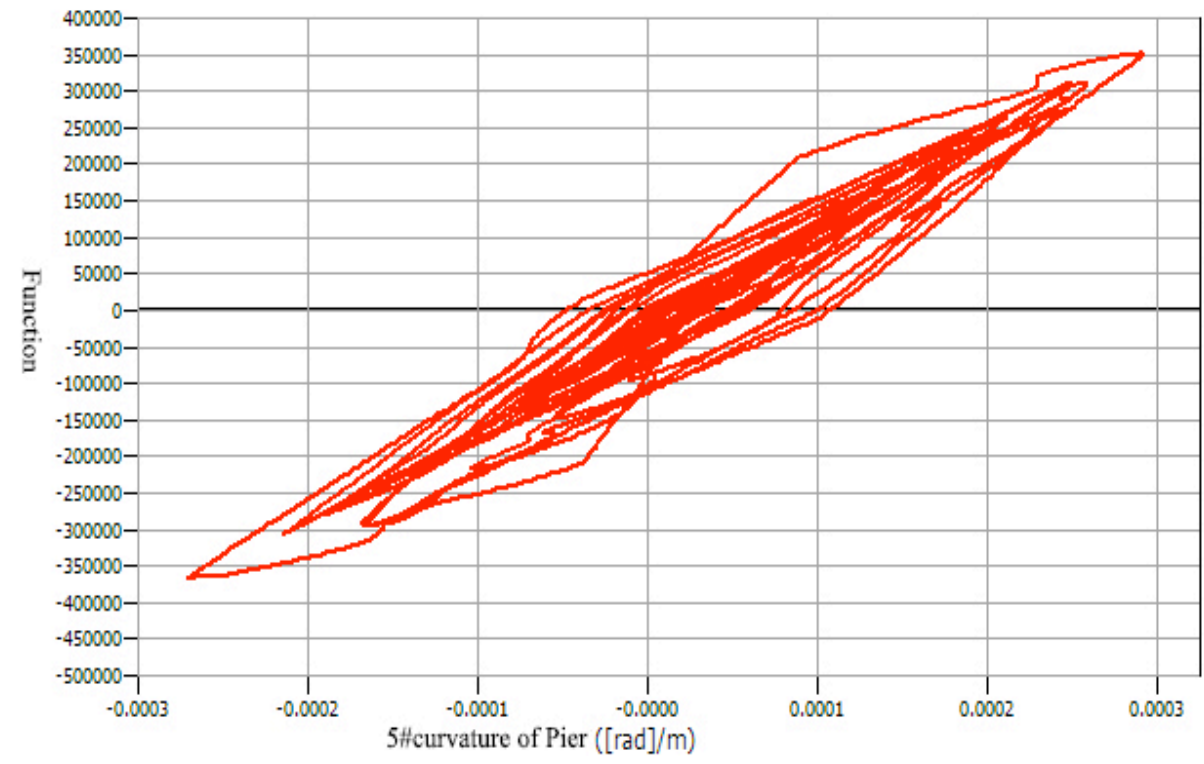

$5 *$ Bending moment of Pie

- Summary -

$\approx \operatorname{Max}: 3.505 e+005$ at 0.000

* Min:-3.689e+005 at $-0,000$

* Unit:kN,m,sec

Fig. (8). End of each pier cross-section bending moment-curvature hysteretic curves.

Table 3. Bending moment-curvature calculation results of each pier.

\begin{tabular}{|c|c|c|c|c|c|c|}
\hline \multirow{2}{*}{ Pier No. } & \multicolumn{2}{|c|}{ Cracking } & \multicolumn{2}{c|}{ Yield } & \multicolumn{2}{c|}{ Destruction } \\
\cline { 2 - 7 } & Bending Moment & Curvature & Bending Moment & Curvature & Bending Moment & Curvature \\
\hline \hline 1 & 2252.33 & 0.00158 & 2714.02 & 0.00166 & 3029.25 & 0.00381 \\
\hline 2 & 181100.23 & 0.00006 & 350500.15 & 0.00031 & 553601.75 & 0.00219 \\
\hline 3 & 114800.43 & 0.00007 & 238902.33 & 0.00032 & 436315.66 & 0.00260 \\
\hline 4 & 187500.43 & 0.00119 & 361800.78 & 0.00268 & 605002.93 & 0.00273 \\
\hline 5 & 85730.19 & 0.00031 & 257900.67 & 0.00125 & 487486.85 & 0.00274 \\
\hline 6 & 1438.22 & 0.00081 & 3236.40 & 0.00199 & 3347.05 & 0.00397 \\
\hline
\end{tabular}

Note: In the table, the unit of bending moment is kN.m; curvature is $\mathrm{rad} / \mathrm{m}$. 
Table 4. Elastic-plastic calculation results for each end of the pier internal force.

\begin{tabular}{|c|c|c|c|c|}
\hline Pier No. & Axial Force (kN) & Shear Force (kN) & Bending Moment (kN.m) & Curvature (rad/m) \\
\hline \hline 1 & 1510.55 & 1794.89 & 16172.29 & $1.40 \mathrm{E}-04$ \\
\hline 2 & 4348.04 & 4935.54 & 69638.58 & $2.53 \mathrm{E}-04$ \\
\hline 3 & 3308.54 & 7063.55 & 99121.86 & $3.06 \mathrm{E}-04$ \\
\hline 4 & 3511.59 & 10473.95 & 138549.47 & $3.90 \mathrm{E}-04$ \\
\hline 5 & 3036.53 & 15953.40 & 164095.50 & $4.26 \mathrm{E}-04$ \\
\hline 6 & 2240.82 & 4480.22 & 33184.89 & $4.65 \mathrm{E}-04$ \\
\hline
\end{tabular}

used in this paper for elastic-plastic analysis, with the duration of $30 \mathrm{~m}$ (the unit of the longitudinal coordinates in the diagram is gal). The input mode is uniform excitation; Newmark- $\beta$ method is used for calculation, damping ratio is 0.05 , and the time step is $0.02 \mathrm{~s}$.

\subsection{Calculation Results of Elastic-Plastic Time History}

The relationship between bending moment and curvature of cross-section at the bottom of each pier is shown in Table 3; the calculation results of internal force at the bottom of each pier are shown in Table 4; the hysteretic curves of each plastic hinge are shown in Fig. (8).

\section{CONCLUSION}

(1) The calculation results of bending moment-curvature show that with the increase in cross-section moment of inertia, the bending moment and curvature increase accordingly and the anti-cracking, yield and destruction capacity become stronger.

(2) It is shown from the elastic-plastic calculation results that the bending moment-curvature hysteretic curves of No.1 Pier and No.6 Pier are linear, indicating that No.1 Pier and No.6 Pier are within the elastic range, not entering the destruction stage; No.2 Pier, No.3 Pier, No.4 Pier and No.5 Pier have entered the yield stage, but not reaching the destruction state.

(3) It shows from the diagram of hysteretic curves that the hysteretic energy dissipation capacity of rectangular thin-wall pier is larger than that of double-column pier; therefore, it is suggested that the rectangular thin-wall pier should be used under the same condition as much as possible.

\section{CONFLICT OF INTEREST}

The authors confirm that this article content has no conflict of interest.

\section{ACKNOWLEDGEMENTS}

This work is supported by the Project of Science and Technology of Western China Communications Construction (2009318000102)。

\section{REFERENCES}

[1] D. Wang, J. Wang, Z. Sun, and X. Li, "Wenchuan earthquake fall simply supported girder bridge beam damage and design countermeasures," Journal of Disaster Prevention and Mitigation Engineering, vol. 5, pp. 595-602, 2011.

[2] H. Wei, Z. Lu, and Z. Wang, "Near-field beam lead rubber bearing isolation characteristics analysis," Journal of Tongji University (Natural Science Edition), vol. 1, pp. 39-44, 2010.

[3] C. Ryan, "Construction handbook gets a rewrite-sweeping change loom for specification guide. sparking debate on impact," Wall Street Journal, New York, N. Y. 2002.

[4] X. Zhu, and H. Jiang, "Bridge pier column base on the performance of the seismic design method," Journal of Civil Engineering, vol. 4, pp. 85-92, 2009.

[5] G. Zhou, C. Cui, B. Liu, and X. Li, "Several near fault bridge in wenchuan 8.0 earthquake failure mode of the preliminary discussion," Journal of Earthquake Defense Technology, vol. 4, pp. 370-378, 2008

[6] J. Li, X. Song, and L. Fan, "Study of application of high bridge pier displacement ductility capacity," Earthquake Engineering and Engineering Vibration, vol. 1, pp. 43-48, 2005.

[7] X. Xia, X. Chen, and C. Wang, "Railway high pier elastic-plastic seismic response analysis," Earthquake Engineering in the World, vol. 24, no. 2, pp. 117-121, 2008. 